\title{
Política e Estratégia nacionais de Defesa: integração e consensos políticos
}

\author{
National Defense Policy and Strategy: \\ integration and political consensus
}

Rev. Bras. Est. Def. v. 4, nº 2, jul./dez. 2017, p. 49-76

DOI: $10.26792 /$ RBED.v4n2.2017.75013

ISSN 2358-3932

\section{ADRIANO PORTELLA DE AMORIM}

\section{INTRODUÇÃO}

A função de defesa nacional do Estado brasileiro está fundamentada em três documentos de referência: a Política Nacional de Defesa, a Estratégia Nacional de Defesa e o Livro Branco de Defesa Nacional. Tais documentos são o resultado da reforma das instituições de defesa ocorrida a partir da Constituição de 1988 e representam significativo avanço da democracia e da consolidação do poder político consagrado na aplicação dos princípios republicanos.

Os mencionados documentos, desde a inovação legislativa de 2010, são quadrienalmente apresentados à apreciação do Congresso Nacional, onde as duas Casas Legislativas são ouvidas e se pronunciam a respeito. Tal rito, considerado como de natureza político-institucional, consolida a partilha de responsabilidades entre Executivo e Legislativo na condução de temas de vital importância para a soberania do Estado brasileiro e para o amadurecimento de suas instituições públicas e políticas, com reflexos na sociedade e no plano das relações internacionais.

A presente abordagem está dividida em três pontos principais. $\mathrm{O}$ primeiro cuida de um conjunto de sugestões teóricas que, embora pertencentes a diferentes correntes de pensamento, podem servir como contribuições metodológicas aplicáveis, direta ou indiretamente, nos estudos sobre defesa e segurança nacionais, considerando a relevância de perspectivas que, ainda que dissonantes e, até mesmo, distantes do pragmatismo com que a temática é costumeiramente tratada. O segundo ponto aborda

Adriano Portella de Amorim - Centro Universitário de Brasília e Faculdade Icesp de Brasília. 
a integração sul-americana em matéria de defesa, sua conjugação com a diplomacia e as noções de constitucionalidade, legalidade e legitimidade, como formas de prevenção contra possíveis distorções que o uso do poder possa despertar. Por fim, o terceiro ponto assinala a relevância do Poder Legislativo na prerrogativa de acompanhar e fiscalizar o Executivo nas medidas afetas à defesa nacional, notadamente quanto ao uso da força e das escolhas políticas.

\section{REFLEXÕES METODOLÓGICAS PARA A INTEGRAÇÃO: EIXOS DE DEFESA E SEGURANÇA}

As noções sobre soberania, defesa nacional e integração estão permeadas de contrastes e negações. São temas de certa maneira conhecidos e experimentados pelas sociedades e pelos meios acadêmicos, mas há grande estranhamento em sua conjugação, tendo em vista que o campo decisório das escolhas se restringe aqueles que, pela representação, exercem o poder político como detentores do poder, isto é, pelas instituições estatais, agentes públicos e políticos. Então, como lidar com os meios persuasivos e dissuasórios - principalmente sob o ponto de vista militar, bélico - e suas interfaces com as vulnerabilidades sociais, no contexto dos processos de integração de povos?

A propósito, o fenômeno da integração constitui um aparente (mas superável) antagonismo que também delimita a temática e fundamenta um dos problemas formulados: a composição de consensos na compatibilização de interesses nacionais nas demandas por integração e defesa dos povos da América do Sul, sob a perspectiva democrática, notadamente quando se trata da elaboração de documentos de política e estratégia nacionais de defesa, visto que seus efeitos, dirigidos ao âmbito interno, não escapam das percepções do plano externo. Essa característica é um marco de transparência e de boa prática republicana na medida em que delineia as bases do pensamento brasileiro a respeito da matéria, o que ocorre oficialmente desde 1996 com a divulgação do histórico Documento sobre Política de Defesa Nacional, cerne da primeira edição da então denominada Política de Defesa Nacional (PDN). ${ }^{1}$

Desse modo, é preciso abordar, de forma crítica, as assimetrias entre as concepções de soberania, defesa e integração nas democracias da América do Sul, com o intuito de identificar as deturpações que possam comprometer o livre caminhar dos povos da região, mediante a instrumentalização indevida do poder político, valendo-se das tentações inerentes aos argumentos que permeiam a globalização, o direito e a economia. Será possível conceber uma política de defesa comum para a América do Sul, consideran- 
do a solidariedade como fundamento da integração? Como os mecanismos de segurança sul-americana interferem nas relações entre os Estados?

Por certo que a modulação que coloca, de um lado, a ortodoxa separação e, de outro lado, a integração e a cooperação, com os elementos transversais de defesa e segurança, ao tempo em que pode constituir fator de assimetrias, funciona como ponto de partida para a formação de consensos para uma atuação conjunta dos Estados, na representação de seus povos, posto que defesa e segurança, numa visão estreita fundamentada no secular conflito (declarado ou não) entre nações, seriam contrapostos ou, no mínimo, estranhos à ideia de integração, ante os interesses envolvidos. A superação ou a construção de um novo dogma parte demonstra que a soberania, ainda que com traços metafóricos, permite a conjugação das noções de defesa, integração e cooperação internacionais.

Mas, para enfrentar tal desafio, não basta a tinta da caneta oficial ou a decisão política de ocasião. É preciso observar a mudança valorativa verificada nos processos históricos das sociedades, e que servem - na contemporaneidade - para suscitar maior participação democrática na definição da agenda política, repercutindo favoravelmente no processo de integração sul-americana.

Portanto, a construção do novo dogma terá de considerar como as democracias sul-americanas conceberam seus conceitos em matéria de integração e quais as assimetrias em relação aos temas defesa e segurança. Logo, a arquitetura desse cenário exige o exame dos mecanismos de integração dos países da Am

A análise histórica também precisa compreender como os mecanismos econômicos interferem na pauta de defesa, segurança e integração, bem como sua influência no processo de globalização, mercadológico e, até mesmo, econômico, tendo em vista que as assimetrias existentes permeiam as instituições políticas e os organismos internacionais. As conjecturas de Furtado (1991) e Vergopoulos (2005) contribuem para entender os refluxos de tais implicações, possibilitando que se verifique que a economia pode ser fórmula de avanço para a integração e a cooperação entre povos, ou retrocesso em termos de subjugação de alianças, visto que secularmente a riqueza das nações move os mais variados conflitos de interesses.

Do político ao econômico, a temática é trespassada pelo jurídico, pelo direito. Neste espaço, as teorias que dizem respeito o desenho político-jurídico-organizacional dos Estados se revestem de singular importância, notadamente para construir ou adaptar os atuais modelos aos novos dogmas, nos planos internos e externo, com as decorrentes apropriações metodológicas de Ferrajoli (2002) e Losano (2007), observando-se as transformações da ordem mundial a partir da chamada crise da soberania ou do 
Estado-Nação e, por conseguinte, das características dos sistemas jurídicos nacionais em face de um desiderato (intangível, no momento) universalizante.

Soberania, defesa e integração são temas que, na contemporaneidade, merecem ser estudados e debatidos conjunta e comparativamente, em razão da interdependência (no mais das vezes negligenciada) e da complexidade de que se revestem. No mundo determinado por instrumentos de mercado que funcionam independentemente da ideologia e do regime político que os países aparentam adotar, tal tripé está situado entre os principais desafios que repercutem no exercício do poder estatal, no funcionamento das instituições e no caminhar das sociedades, pois estão associados aos processos de globalização, às iniciativas que transformam as normas jurídicas e aos interesses que interferem na ordem econômica.

Da colonização aos regimes de exceção, da democratização ao estabelecimento de mercado comum ou de regras de direito comunitário, a trajetória sul-americana ainda não alcançou pleno processo de integração. Há aparentes tolerâncias e um disfarçado estranhamento que ainda colocam os povos distantes da composição de uma comunidade que possa se integrar econômica, política, social e culturalmente, o que levaria a um natural e gradual processo de integração jurídico-normativo.

$\mathrm{Na}$ atualidade, é preciso examinar a clivagem colocada na discussão entre soberania, defesa e integração, para melhor compreender as escolhas feitas pelos Estados e por seus governantes, comparando-as com as demandas dos indivíduos e das sociedades. A conjugação suscitada abre caminho para a análise da compatibilidade entre políticas públicas e princípios adotados pelas sociedades.

De igual modo, a globalização (ou o que ainda se considera como tal) merece ser vista além dos aspectos comerciais e econômicos, mas sim como processo de relacionamento internacional de povos com respeito à diferença (em suas variadas formas), inclusive sob o ponto de vista de crescimento e desenvolvimento econômico, discutindo-se modelos multiculturais, etnocêntricos e o fenômeno da endocolonização, os quais, disfarçados, contaminam o diálogo franco que é indispensável à formação de amplos consensos. Nessa ordem de ideias, para compreender o que somos e o que poderemos vir a ser, são sempre bem-vindas as contribuições de Carvalho (2006), Clastres (2010), Rawls (2002), Ribeiro (2006) e Santos (1989).

No cenário sul-americano essas circunstâncias ganham especial envergadura, pois os Estados, de genealogia colonial e absolutista, vivenciaram momentos de conflitos e revoluções por independência e soberania, permeados por processos de aculturação e embates para a preservação de minorias e superação de práticas escravocratas, com territórios fragmen- 
tados, de um lado, em língua espanhola e, de outro, integrado pela língua portuguesa (o Brasil), tendo todos alcançado estabilidade com predomínio do modelo democrático presidencialista, cujo exercício do poder transita entre esquerda, centro e direita, registrando-se, no curso histórico, ocorrências de regimes de exceção.

Um alerta: a temática não pode se limitar a aspectos de ordem militar, bélica, de hegemonia ou enfrentamento entre Estados, pois é interdisciplinar e, portanto, deve considerar a perspectiva da integração regional a partir da ruptura paradigmática a partir da qual segurança e defesa transcendem a esgotada noção de proteção unilateral dos estados nacionais. De fundo jurídico-social, a abordagem precisa desvelar se as políticas e decisões governamentais correspondem aos anseios das sociedades, posto que as expectativas pertencem ao múltiplo universo das relações e necessidades humanas. A experiência democrática merece lugar de destaque, pois, mesmo que imperfeita e inacabada, há de ser considerada como um dos principais elementos de integração. Nesta perspectiva, a conjugação dos pensamentos de Aguiar (2000), Bobbio (2003; 2006), Borges (2005), D’Araujo e Castro (2000), Lewandowski (2004), Müller (2004) e Silva (2000).

Os aspectos culturais (intercâmbios) não podem ser negligenciados porque, para compreender o espírito da integração e suas repercussões nas noções de soberania e defesa, é preciso transitar pelos fenômenos da aculturação, da endoculturação e da endocolonização para verificar se o que se pretende é um modelo de mútua cooperação ou de dominação e hegemonia sob a aparência de convivência harmoniosa. Virilio e Sylvere (1984) são decisivos para ajudar na compreensão dessas conjecturas.

Para o campo do direito interessa, em especial, as conjecturas a respeito de compartilhamento, supraestatalidade e fragmentação em confrontação com os princípios democráticos e, por conseguinte, sua aplicação prática em termos de direitos da pessoa humana e o que é feito com o poder político que decorre da soberania popular, na equação representativa e na relação de responsabilidades entre detentores e destinatários do poder político, isto é, entre políticos e cidadãos, respectivamente, na democracia em larga escala. Os estudos de Coni (2006), Lefort (1991), Maliska (2006) e Dahl (2009) tornam possível o delineamento dessas questões.

As reflexões teóricas não poderão desprezar temas em ebulição na contemporaneidade, tais como os aspectos de ordem econômica e o papel dos Estados, estabelecendo-se as conexões com as recentes inovações introduzidas no cenário regional, como o Mercado Comum do Sul, o Parlamento Sul-Americano, a União das Nações Sul-Americanas e o Conselho de Defesa Sul-Americano, ponderando-se como seus princípios orientam as políticas públicas para o fortalecimento da democracia, da integração e da 
paz na região. Ferreira (2003) e Rocha, Domingues e Ribeiro (2008) contribuem para o amadurecimento dessas perspectivas.

Dentro de suas tradições como Estado independe e soberano, o Brasil adota postura voltada à composição de consensos, tendo cumprido o seu dever de casa. No recorte temporal da Constituição de 1998, promoveu a divulgação, em 1996, do Documento sobre Defesa Nacional, a primeira PDN, em 2005 e, há mais de uma década, passou a trabalhar com as suas Política de Defesa Nacional (PND), ${ }^{2}$ Estratégia Nacional de Defesa (END) ${ }^{3}$, bem como, numa postura inédita de participação direta do Congresso Nacional brasileiro, encaminhou ao Legislativo as propostas de atualização das referidas Política e Estratégia, bem como do seu Livro Branco de Defesa Nacional (LBDN), ${ }^{4}$ além de legitimar o funcionamento da União das Nações Sul-Americanas e do Conselho de Defesa Sul-Americano, destacando-se o encontro do Conselho, realizado em 4 de dezembro de 2012, no qual foi aprovado o Plano de Ação para 2013, com destaque para os seguintes eixos: Políticas de Defesa, Cooperação Militar, Ações Humanitárias e Operações de Paz, Indústria e Tecnologia da Defesa e Formação e Capacitação.

Para as perspectivas metodológicas brasileiras de integração nos eixos de defesa e segurança, revela-se a pertinência de perquirir se a noção de defesa, como prerrogativa da soberania, afasta ou estimula as possibilidades de integração dos povos, em especial os da América do Sul. Por certo que a projeção internacional do Brasil há de ser objeto de observação, considerada sua posição econômica, territorial e geopolítica na região. O desafio está em inverter uma ordem até então predominante no globo: prosperar sem oprimir e exercer a democracia sem deturpar seus princípios.

No caso brasileiro, a democracia tem preponderado como ponto de equilíbrio para afastar conflitos e compor amplos consensos em matéria de defesa e segurança. E, nessa linha, o tripé formado pela PND, pela END e pelo LBDN, na qualidade de documentos fundantes do ciclo contemporâneo de transparência, controle social e inserção do poder político como ator decisório e efetivamente responsabilizável, proporcionam um conjunto de elementos imprescindíveis ao processo permanente de reforma das instituições.

As atuais formulações para os novos textos da PND e da END estão sob o exame do Poder Legislativo, cumprindo a temporalidade quadrienal de sua submissão, considerando o novo critério introduzido pelo $\$ 3^{\circ}$ do art. $9^{\circ}$ da Lei Complementar $n^{\circ} 97$, de 9 de junho de 1999, com a redação dada pelo art. $1^{\circ}$ da Lei Complementar $n^{\circ} 136$, de 25 de agosto de 2010. A Política, inaugurada em 1996 e reformulada inicialmente em 2005, está na sua quarta edição, enquanto que a Estratégia alcança o seu terceiro núme- 
ro. Essa breve cronologia demonstra a significativa evolução do Brasil em matéria de transparência e reforma de instituições para os temas de defesa e segurança nacionais, antes herméticos e clivados a um grupo restrito de interessados e especialistas.

Com base nessas premissas, o tópico seguinte apresenta duas peculiaridades a respeito das propostas de atualização da PND e da END, à guisa de reflexão.

\section{INTEGRAÇÃO SUL-AMERICANA E DOCUMENTOS ESTRUTURANTES DE DEFESA}

Naturalmente, a política e as estratégias para a defesa nacional devem guardar compatibilidade e se submeter à Constituição, isto é, a seus princípios, instituições, mecanismos de controles verticais e horizontais, intra e extra órgãos, autoridades e, por conseguinte, nas perspectivas da integridade e da representatividade, ao poder político (Loewenstein, 1986). Logo, a sua natureza, hermeneuticamente falando, correspondente a do próprio tex to constitucional como documento histórico, político e jurídico, em constante aprimoramento ao longo de sua experimentação.

Comparativamente aos textos anteriores, as atuais propostas de PND e END trazem uma significativa mudança de forma e de conteúdo. A estrutura e a redação são mais precisas e revelam preferência por maior pragmatismo e aproximação com linguagem de maior precisão e concisão, de cunho mais próximo à linguagem militar, com a clara intenção de não deixar margem de dúvida quanto aos fins a que se destinam.

De se destacar, também que, apesar de manter a coerência conceitual, terminológica e argumentativa das edições anteriores, os textos de atualização de PND e END apresentam a preocupação com os cenários contemporâneos de tensões internas e externas, os quais podem motivar o emprego dos meios de defesa, direta ou indiretamente. A estabilidade democrática e a solução pacífica de controvérsias são fundamentais para também manter a regularidade do pensamento e das ações de defesa e segurança, posto que, uma vez desequilibradas aquelas, amplia-se e diversifica-se a gradação de mecanismos para enfrentar os possíveis ou manifestos conflitos.

De notar que, em termos de aprovação por meio de decretos autôno$\operatorname{mos}^{5}$ editados pelo Presidente da República em face de sua competência privativa para a matéria, estão formalmente em vigor os textos de 2005, da então PDN, ${ }^{6}$ e de 2008, da END. ${ }^{7}$ Por outro lado, os textos da PDN e da END que inauguraram, em 2012, o modelo de apreciação quadrienal do Poder Legislativo, mediante encaminhamento do Poder Executivo, foram objeto de aprovação ${ }^{8}$ por parte do Congresso Nacional. 
As propostas de PND e de END que compõem o segundo ciclo de quadrienalidade estão disponíveis para consulta pública e sob o exame do Congresso Nacional, tendo recebido manifestação no âmbito da Comissão Mista de Controle das Atividades de Inteligência. ${ }^{9} \mathrm{O}$ presente artigo procura trazer à reflexão aspectos que compõem contextos desses documentos: a integração sul-americana e as escolhas políticas. É o que será abordado na sequência.

\section{Integração sul-americana e conexões globais}

Como princípio constitucional de regência para as relações internacionais brasileiras, ${ }^{10}$ a integração sul-americana compreende variáveis econômicas, políticas, sociais e culturais dos povos da América Latina. A intenção é formar uma comunidade latino-americana de nações, conjugada e complementada pelos princípios de independência nacional, de prevalência de direitos humanos, de autodeterminação dos povos, de não intervenção, de igualdade entre os Estados, de defesa da paz, de solução pacífica dos conflitos, de repúdio ao terrorismo e ao racismo, de cooperação entre os povos para o progresso da humanidade e de concessão de asilo político. ${ }^{11}$ Não se trata de simples previsão programática, mas sim de escolhas fundantes da República que demonstram os patamares políticos do Estado brasileiro perante a si mesmo e às demais nações, em especial as sul-americanas.

O caminho para alcançar e manter a plenitude desses princípios não pode ser outro senão o da democracia, ao fundamento de regras republicanas. E, pela via democrática, não se pode forçar o processo histórico de escolhas políticas e sociais de cada Estado soberano, como também não se pode uniformizar a comunidade, isto é, as diferenças e os diferentes devem ser mais do que tolerados: devem ser reconhecidos e inseridos até que as singulares não sejam percebidas ou não tenham qualquer significância para a convivência.

Logo, integração, democracia e respeito às diferenças permitem a superação de conflitos por meio de consensos. Essa fórmula, se não supera, estabiliza e mitiga interesses que possam levar à beligerância explícita, na medida em que amplia a confiança recíproca e consolida a paz na região. À propósito, seguindo as reflexões de Kant (2004, 126-127), ameaças constantes (ainda que não manifestas) dificultam a paz duradoura e a omissão de hostilidades não significa garantia de paz, visto que o silêncio pode conduzir à preparação para um enfrentamento (ainda que hipotético), de tal modo que a perspectiva do filósofo prussiano assinala o condicionante do modelo republicano de liberdade, dependência e igualdade como fundamento de segurança mútua, isto é, de um contrato de reciprocidade. 
Embora Bobbio $(2006,207)$ tenha uma visão cética quanto à factibilidade de um sistema internacional amplamente democrático e republicano que proporcione a paz duradoura, reconhece que a democratização das sociedades está em curso. Mas é bom lembrar que quando se trata de sociedades democráticas republicanas, o argumento é o de que os mesmos valores e princípios possam servir para orientar a solução pacífica de controvérsias; todavia, a multiplicidade de modelos democráticos e o antagonismo de interesses nacionais podem comprometer arranjos cooperativos.

Os princípios constitucionais brasileiros ao tempo em que marcam a retomada do modelo democrático de 1988 e confirmam a escolha pela paz na região sul-americana, superam a página dos conflitos que marcaram, no passado, os povos da América do Sul, notadamente em decorrência da fragmentação e das disputas territoriais que caracterizaram o período colonial e as guerras em que o país participou.

O constitucionalismo brasileiro, mais do que eleger um princípio de convivência junto aos povos do subcontinente americano, faz uma solene declaração de paz permanente e de repúdio a processos que envolvam o uso de força para resolver conflitos de interesses com as nações amigas. Esses são os fundamentos que orientam a defesa nacional brasileira, os quais permeiam as políticas e estratégicas que deles derivam, de modo a guardar compatibilidade com a Constituição.

A integração sul-americana é um dos sustentáculos da paz duradoura, ainda que a paz possa ser negativamente considerada como suspensão da beligerância explícita. Integrar sistemas democráticos diferentes constitui o mote político e estratégico para prevenir e afastar conflitos. Não se trata, aqui, de unificar ideologias de esquerda, de centro ou de direita, mas de alinhar posturas democráticas em torno de objetivos comuns e equilibrados.

Não é por acaso que, notadamente na América do Sul, a democracia foi eleita como base de suas relações econômicas que, na prática, repercutem e influenciam os demais aspectos das dinâmicas político-institucionais, na essência do compromisso democrático ${ }^{12}$ e da cláusula de prevenção contra a sua ruptura, firmados no âmbito do Mercado Comum do Sul. ${ }^{13}$

Nesse contexto, é sempre oportuna a lembrança do septuagenário Tratado Interamericano de Assistência Recíproca, ${ }^{14}$ de 1948 , celebrado ${ }^{15}$ ao fundamento da defesa hemisférica três anos depois do fim da Segunda Grande Guerra. Também são de relevância para os cenários geopolíticos de paz, cooperação, defesa e segurança internacionais, o Tratado sobre a Não-Proliferação de Armas Nucleares, ${ }^{16}$ o Tratado de Cooperação Amazônica ${ }^{17}$ e os acordos de cooperação em matéria de Defesa firmados pelo Brasil, de forma bilateral, com Peru ${ }^{18}$ e Argentina. ${ }^{19}$

Veja-se o texto proposto na PND a respeito da integração. 
No contexto da PND, figuram duas posições fundamentais que merecem maior reflexão: $1^{a}$ ) os princípios de solução pacífica de controvérsias, de promoção da paz e de segurança internacionais, bem como de multilateralismo e de integração sul-americana; $\mathcal{2}^{\mathrm{a}}$ ) por outro lado, esses princípios são conjugados com o princípio de projeção do país no concerto das nações, além da ampliação de sua presença em processos decisórios internacionais, assinalando a necessidade de continuado esforço entre as áreas diplomática e militar. ${ }^{20}$ Haveria um aparente antagonismo entre essas duas posições?

Se sim, seria decorrência de hipotética e infundada contradição com a aplicação dos princípios constitucionais brasileiros em matéria de relações internacionais. Portanto, não há que se falar em contradição ou assimetria, vez que, cotejando a primeira com a segunda posição, o modelo constitucional-democrático brasileiro é compatível com os mecanismos de equilíbrio e reciprocidade presentes no concerto das nações, notadamente quanto a posturas ou medidas internacionais voltadas ao direito humanitário internacional, isto é, ao respeito à dignidade da pessoa humana. Somente o colapso do sistema republicano-democrático, de relações e de garantias internas e externas, ou seja, o extremo imponderável da emergência decorrente de conflito global ou de ameaças não contidas pela cooperação e diplomacia poderia provocar a mitigação desses princípios.

Semelhantemente, tais enunciados também correspondem às hipóteses de ajuda humanitária e operações de paz que possam conduzir o Brasil a ampliar sua participação nesses eventos, o que poderia aumentar sua influência política internacional mediante o fortalecimento dos laços de cooperação. ${ }^{21} \mathrm{O}$ protagonismo brasileiro, na linha de sua tradição, situa-se no campo da mediação e da busca de soluções ponderadas pela via diplomática de composição de interesses, mesmo porque a adoção de postura diferente poderia caracterizar o país como fonte de ameaça a ideologias extremistas, de ordem externa ou interna, tornando o território nacional e sua população alvo de ações criminosas, tais como o terrorismo.

A integração regional volta a ser tratada como peça principal para prevenir e mitigar uma possível militarização do Atlântico Sul, área na qual a soberania brasileira sobre os recursos naturais há de ser sustentada apesar da escassez de oferta desses bens em termos globais, de tal modo que sanções políticas e econômicas devem ser equilibradas com estruturas de defesa que desencorajem conflitos armados ou ações fraudulentas, criminosas, praticadas contra os interesses nacionais, consideradas essas ações pela PND como não legítimas. ${ }^{22}$

O desafio brasileiro reside, portanto, em conjugar seus princípios constitucionais com a negativa de acesso ou a compartilhamento de bens e riqueza naturais com a comunidade internacional. Por conseguinte, a atua- 
ção brasileira no subcontinente não se orienta em modelo imperialista de subjugação, mas sim de Estado comprometido com a paz e a segurança internacionais, a prevalência dos direitos humanos e a capacidade de mediar conflitos, modulando os seus efeitos. ${ }^{23}$ Esses enunciados estão compreendidos e harmonizados com os objetivos nacionais de defesa, consubstanciados na contribuição para a estabilidade regional e para a paz e a segurança, assim como para o incremento da projeção do Brasil em processos decisórios internacionais. ${ }^{24}$

Por sua vez, a END prevê medidas específicas para a integração regional, complementando as previsões da PND. Dentre os objetivos nacionais de defesa (OND), destaca-se a Estratégia de Defesa (ED) $n^{\circ} 11$, que se refere à promoção da integração regional. Tal estratégia tem a finalidade de consolidar "uma mentalidade própria de defesa no âmbito da América do Sul”, de modo a que possam elevar os compromissos dos países do bloco na conjugação de esforços para a solução de problemas comuns. ${ }^{25}$

A ED $n^{\circ} 11$ encontra-se detalhada em ações estratégicas de defesa (AED) específicas, que se dirigem a: (i) Estimular o desenvolvimento de uma identidade sul-americana de defesa ${ }^{26}$, (ii) intensificar as parcerias estratégicas, a cooperação e o intercâmbio militar com as Forças Armadas dos países da Unasul $^{27}$ e (iii) Incrementar a participação brasileira no CDS/Unasul. ${ }^{28}$

A previsão de um pensamento consolidado - embora não uniformizado e clivado de defesa, em face das características dos países e das necessidades específicas de emprego de meios militares - aproxima a temática da linha teórica que estuda eventual criação de modelo de defesa comum (Silva 2000) destinando a ampliar, consolidar e institucionalizar composições multilaterais dos países da região, preservando-se as soberanias nacionais e afastando, por impraticável, qualquer possibilidade de compartilhamento do poder soberano em suas vertentes (ex.: política, territorial e militar).

Embora a PND e a END não mencionem expressamente essa possibilidade, tal temática pode vir a ser debatida no âmbito do Conselho de Defesa Sul-Americano (CDS) da União de Nações Sul-americanas (Unasul), preservando-se as escolhas de cada Estado, cotejando-se vantagens e desvantagens estratégicas em termos de vulnerabilidades para a América do Sul já pacificada, observando-se cenários geopolíticos mais amplos e o custo de recursos humanos e orçamentários. ${ }^{29}$

O pragmatismo brasileiro em matéria de integração regional não exclui a pretensão de manter o Brasil na sua tradição de respeitabilidade para além do subcontinente americano visto que, para a garantia de seus princípios constitucionais internacionais, inclusive para efeito de defesa a partir da prévia harmonização e composição de consensos, é necessário ampliar e 
fortalecer os laços de cooperação com outros países, regiões e blocos globais. Nessa perspectiva, a ED n ${ }^{\circ} 12$ também preconiza AED's específicas, a saber: (i) intensificar as medidas de fomento da confiança mútua e da segurança internacionais; ${ }^{30}$ (ii) intensificar a realização de intercâmbios e acordos na área de defesa com outros países; ${ }^{31}$ (iii) intensificar a realização de operações internacionais, unilateralmente ou em arranjos plurilaterais, e de iniciativas de cooperação em áreas de interesse de defesa; ${ }^{32}$ (iv) intensificar a atuação em foros multilaterais e em mecanismos inter-regionais; ${ }^{33}$ e (v) incrementar a participação brasileira nas decisões sobre o destino da região Antártica. ${ }^{34}$

A propósito, ao abordar a importância de levar a sério o direito internacional em face da crise do Estado nacional, Ferrajoli (2002, 47) faz um relevante alerta para a importância dos processos de integração através do direito: as soberanias, ainda que democráticas, estão marcadas pela desigualdade que, por sua vez, em razão das assimetrias entre países ricos e pobres, conduz à perda de legitimidade na medida em que as promessas universais de igualdade, liberdade e tolerância não são satisfatoriamente cumpridas, interna e externamente, o que leva à precarização da cooperação e, por conseguinte, da paz. Portanto, o sistema de direitos funciona como garantidor das funcionalidades do modelo de solução dialogada de controvérsias e composição de conflitos de interesses.

Desse modo, a integração sul-americana e as conexões globais presentes na PND e na END colocam para o Brasil a reflexão sobre a necessidade de permanente acompanhamento do equilíbrio e do respeito à soberania nas relações entre os países da região sul-americana, sem perder de vista os princípios constitucionais que regem suas relações internacionais, inclusive no campo da defesa nacional. É, pois, nesse contexto que se verifica a relevância da atuação do Parlamento brasileiro, o que será tratado na sequência.

\section{Poder político: dimensões de legalidade e legitimidade}

Tangenciando uma linha argumentativa de Schmitt (1968) que aborda o extremo da separação entre legalidade e legitimidade, a colocar, de um lado, a conformação e a inércia em face de um dado quadro político-institucional relevante condicionado ao status quo normativo e, de outro lado, a possibilidade de sua superação pelo poder de uma força transformadora que transcende a liturgia vigente, adotemos, aqui, o caminho do equilíbrio e da normalidade para convergir legalidade e legitimidade como elementos genealógicos do poder político lastreado em decisões abrangentes, vinculantes, formadas por consensos democráticos e que se revistam de caráter normativo, excluindo-se qualquer tipo de viés autoritário do Estado. 
O poder político, fundamentado e exercido sob essas perspectivas, representa a noção de vontade concretizada segundo critérios material e processualmente definidos, integrantes do núcleo normativo que, na linha de Müller (2004, 125-126), afasta o voluntarismo, o normologismo e o decisionismo, prevalecendo o direito e a Constituição. Apesar de esse desenho de positivismo jurídico ser criticável por sua rigidez conformadora, para o campo da defesa nacional é de grande utilidade porque, se não afasta totalmente, ao menos dificulta a ocorrência de práticas não republicanas de instrumentalização deturpada de políticas e estratégicas nas temáticas de defesa. $\mathrm{O}$ exercício da vontade está vinculado à observância da norma e do rito, seja no campo político, seja no campo institucional. O objetivo é prevenir arbitrariedades.

Tanto na PND quanto na END há o emprego de uma singular expressão: a "vontade nacional”. Na Política, está presente nos fundamentos ${ }^{35}$ e nos objetivos nacionais de defesa. ${ }^{36} \mathrm{~A}$ seu turno, a Estratégia veicula a terminologia nos fundamentos do poder nacional. ${ }^{37}$ Em que consiste essa vontade e quais as bases de sua legitimidade? Seguindo teorização de Müller (2004, 106) segundo a qual "todo o poder do Estado emana do povo e: que o povo, o próprio povo, teria imposto a si mesmo tudo isso, por força de seu poder constituinte", a vontade não teria outra natureza senão a de fundamento que legitima a vinculação aos elementos da Constituição, de sua linguagem, de suas normas e de seus procedimentos. A vontade não é aleatória, posto que, por princípio, se encontra previamente normatizada e procedimentalmente estabelecida no texto constitucional.

O texto da PND submetida à apreciação do Congresso Nacional assinala, em seus fundamentos, que a Política é coordenada pelo Ministério da Defesa (ente que representa um dos pontos mais significativos da recente reforma das instituições de defesa nacional no Brasil) em articulação com as demais políticas nacionais, reforçando a tradição do país em considerar a interdependência e a complementaridade da função defesa nacional, isto é, sua envergadura não permite que seja considerada clivada ou considerada como sistema fechado em si mesmo para alcançar seus próprios objetivos. Logo, a PND é um subsistema político-institucional de ampla envergadura e atuação horizontal (e não vertical) com outras políticas de Estado. $\mathrm{Na}$ política, a "vontade" é elemento de orientação dos objetivos nacionais, conforme a seguinte previsão contida em seus fundamentos: ${ }^{38}$

Coordenada pelo Ministério da Defesa, a PND articula-se com as demais políticas nacionais, com o propósito de integrar os esforços do Estado brasileiro para consolidar seu Poder Nacional, compreendido como a capacidade que tem a Nação para alcançar e manter os Objetivos Nacionais, em conformidade com a Vontade Nacional. 
Manifesta-se em cinco expressões: a política, a econômica, a psicossocial, a militar e a científico-tecnológica (grifo nosso).

A conjugação de esforços tem a finalidade de garantir a plenitude do chamado poder nacional, do qual a "vontade" constitui elemento indutor, conceituado da seguinte forma pela END: ${ }^{39}$

O Poder Nacional apresenta-se como a conjugação interdependente de vontades e meios, voltada para o alcance de determinada finalidade. De vontades, por ser este um elemento imprescindível à sua manifestação, tornando-o um fenômeno essencialmente humano, individual ou coletivo; de meios, por refletir as possibilidades e limitações das pessoas que o constituem e dos recursos de que dispõe.

Assim, entende-se o Poder Nacional como a capacidade que tem a Nação para alcançar e manter os Objetivos Nacionais, em conformidade com a vontade nacional, manifestando-se nas Expressões Política, Econômica, Psicossocial, Militar e Científico-tecnológica (grifo nosso).

Na PND, a "vontade" também está presente em um dos objetivos nacionais de defesa. ${ }^{40}$ Veja-se:

Garantir a soberania, o patrimônio nacional e a integridade territorial. Trata-se de assegurar a condição inalienável de fazer valer a vontade nacional e de exercer a última instância da autoridade do Estado, sobre o conjunto das instituições, bens nacionais, direitos e obrigações, valores e costumes, bem como a estabilidade da ordem jurídica em todo o território nacional (grifo nosso).

Da leitura desses enunciados, é possível constatar que a "vontade” é a representação do poder político que, por sua vez, é a essência da soberania popular. Na democracia constitucional brasileira, a conjugação de poder político, poder nacional e soberania popular constitui fundamento de legalidade e legitimidade da PND e da END, que se exercitam por meio das instituições nacionais, públicas e políticas, para os quais devem ser aplicados controles horizontais e verticais para prevenir, mitigar e combater desvios de finalidade, lembrando que o extremismo de uma dada "vontade" pode levar a distorções do modelo republicano, com rupturas institucionais e fórmulas revolucionárias de solução de conflitos que tenham o potencial de colidir com os mecanismos constitucionais que garantem a normalidade do sistema democrático. 


\section{ESCOLHAS POLÍTICAS E CONGRESSO NACIONAL}

Escolhas políticas pertencem ao universo de atuação do poder político e sua vinculação às prerrogativas do Estado em colocar em prática, mediante normas e políticas públicas, escolhas valorativas de determinado povo, consubstanciadas em modelos republicanos de democracia presentes na Constituição e em seus procedimentos, o que é, na prática, a vontade tratada no tópico anterior. Essa noção representa escolhas de natureza fundamental, que orientam e delimitam as prerrogativas e o uso do instrumental coercitivo do Estado. $\mathrm{O}$ modelo brasileiro não cogita a existência de inimigos internos e externos, mas sim princípios e instituições a serem defendidos, de tal modo que afasta qualquer nuance emergencial de decisionismo emergencial estudado por Schmitt (2001).

Política, poder político e normas jurídicas não estão isentas de ideologias. São inevitáveis em qualquer regime de governo. O desafio é equilibrar perspectivas e evitar contaminação de princípios. Da teorização apresentada por Villoro $(1985,20)$, ideologia funciona como estratégia, um método (ainda que não científico) de formular e defender posições políticas. Politização conduz à divisão, que é essência da democracia; mas é preciso cautela com os campos de embates para prevenir rupturas democráticas a partir de seu próprio sistema de acessos (Diáz Revorio 1997).

Essas percepções adquirem especiais contornos no campo da defesa nacional. A PND e a END, na qualidade de documentos estruturantes de defesa, tanto na fase de formulação no Executivo quanto na de apreciação no Legislativo, merecem tratamento epistemológico que lhes garanta o equilíbrio político-institucional. É essa fórmula que se tem praticado para assuntos de defesa nacional, mantendo-se o processo de amadurecimento das instituições para as temáticas tratadas.

Por outro lado, há estudos que suscitam a ampliação do embate ou disputa política para a construção de políticas e estratégias de defesa, de modo a tornar o Legislativo protagonista em posição horizontal ao Executivo, modificando-se uma dada posição heterônoma e minimalista (Oliveira 2007). Mas o risco é de que a politização transborde a seara do Legislativo e repercuta efeitos indesejáveis na estabilidade de áreas e instituições especializadas, tais como as Forças Armadas (Carvalho 2005, 135-136), que devem manter equidistância de disputas políticas, preservando-se os aspectos de ordem constitucional e científica que subsidiam a tomada de decisão por parte dos órgãos competentes do Estado, na linha da tradição republicana brasileira. ${ }^{41}$

O Congresso Nacional não necessariamente aprova, mas essencialmente aprecia os textos da PND e da END, como também do LBDN. Isso 
porque, não se trata de matérias submetidas ao tradicional rito do processo legislativo, mas sim ao que se pode denominar de devido processo político-institucional, na medida em que no Poder Legislativo reside a competência de aprovação de orçamentos aplicáveis à função defesa nacional, bem como as prerrogativas de fiscalizar, concretamente, programas, projetos e políticas do Poder Executivo, no qual estão inseridas as instituições de defesa, como o Ministério da Defesa e os Comandos da Marinha, do Exército e da Aeronáutica.

A última apreciação conclusiva dos textos da PND e da END pelo Parlamento deu-se na forma do Parecer $n^{\circ}$ 51, de 2012-CN, da Comissão Mista de Controle das Atividades de Inteligência do Congresso Nacional, onde foram tecidas recomendações encartadas na edição do Decreto Legislativo $\mathrm{n}^{\mathrm{o}} 373$, de 2013, assinalando-se a pertinência de, entre outros tópicos, acrescer à PND o conceito de segurança nacional (a compreender a defesa externa, como "defesa nacional”; e a segurança interna "quando ameaças são provenientes de pessoas ou organizações estabelecidas no interior do território de um país") e de poder nacional (conforme explicitado no item 2.2, acima), o que foi adotado nos atuais textos. No referido parecer há menção de que o Poder Legislativo deva ter maior participação na elaboração e na fiscalização do Poder Executivo quanto às medidas previstas na PND.

$\mathrm{Na}$ atual fase de apreciação da PND, da END e do LBDN, o Parecer (CN) $n^{\circ}$ 1, de 19 de outubro de 2017, da Comissão Mista de Controle das Atividades de Inteligência do Congresso Nacional, já indica a necessidade de evoluir a abordagem sobre o instituto da garantia da lei e da ordem (GLO), num indicativo de que o Legislativo dirige suas atenções à recorrência desse instrumento que, embora constitucionalmente previsto ${ }^{42}$ para situações especiais e episódicas, ${ }^{43}$ tem revelado possíveis disfunções no sistema de segurança pública, fazendo com que os meios militares de defesa nacional sejam cada vez mais empregados em ações de GLO, o que pode, no limite, levar a estudos sobre uma possível revisão da repartição de competências entre os níveis federal, estadual e municipal. Entretanto, há de se ter muita cautela quando se trata de GLO, porque tal forma de emprego das Forças Armadas se dirige ao campo interno, razão pela qual não integra o núcleo finalístico da função defesa nacional, que cuida, como se sabe, das ameaças externas, sejam efetivas ou potenciais.

Há outro ponto da END que merece destaque no contexto das prerrogativas do Congresso Nacional: a partilha de atuação entre as áreas de diplomacia e de defesa nacional. ${ }^{44}$ Eis o trecho:

O Setor de Defesa, constituído pelo Ministério da Defesa e integrado pela Marinha do Brasil, pelo Exército Brasileiro e pela Força 
Aérea Brasileira, é responsável pelo preparo e pelo emprego da expressão militar do Poder Nacional. Assim, se, por um lado, nos tempos de paz, o Setor de Defesa atua de maneira a contribuir para as ações de diplomacia empreendidas pelo País, por outro lado, em caso de guerra ou conflito armado, é o setor do Estado brasileiro que aplica a força em sua plenitude (grifo nosso).

Na primeira parte ("tempos de paz”) do excerto acima transcrito, nota-se a conjugação entre as áreas de diplomacia e de defesa nacional. Na segunda parte ("caso de guerra ou conflito armado"), a redação adotada, embora não mencione expressamente, a diplomacia está presente, posto que, ainda que o setor (função) de defesa nacional venha a ser autorizado pelas instituições competentes do Estado a exercer a prerrogativa de aplicar "a força em sua plenitude”, as correspondentes medidas não afastam a articulação com a diplomacia, inclusive no binômio civil-militar/militar-civil, sem esquecer as competências do Presidente da República e do Congresso Nacional, além da atuação do Conselho da República ${ }^{45}$ e do Conselho de Defesa Nacional ${ }^{46}$. Logo, a arquitetura do setor de defesa compreende um conjunto de instituições constituídas, legitimadas e representativas de poder.

Isso porque, no constitucionalismo democrático, ainda que deflagrada uma guerra ou instaurado um conflito armado, a diplomacia não deixa de ser aplicada, visto que a composição de interesses, ainda que com o uso da força, não dispensa a realização de diálogos, mesmo que infrutíferos em dado momento, os quais não podem ser desprezados como caminho para impedir, atenuar ou interromper atos de guerra ou de conflitos, uma vez que o uso da força não se prolonga indefinidamente, em decorrência do exaurimento de seus meios e os efeitos que acarreta. A diplomacia, secularmente, é o ponto de equilíbrio e o canal de representação do poder do Estado no exercício da soberania, observados os princípios de direito humanitário.

Nas escolhas políticas, vigora a presunção de que todas as instituições (da diplomacia à defesa, do Executivo ao Legislativo) estão sujeitas ao império do direito e, por conseguinte, à força, aos procedimentos e aos limites da Constituição.

\section{CONSIDERAÇÕES FINAIS}

O presente artigo tratou de determinadas peculiaridades dos textos da PND e da END que estão sob a apreciação do Congresso Nacional, destacando-se a importância dos processos de integração regional e de cooperação internacional como mecanismos de estabilidade e, por conseguinte, de prevenção e constância da paz. Também foram trazidos apontamentos a 
respeito da importância da conjugação entre diplomacia e defesa nacional, seguindo também a tradição brasileira em matéria de defesa externa.

No contexto tanto da PND quanto da END foram assinaladas as prerrogativas do Congresso Nacional para a apreciação dos respectivos textos, bem como para atuar no acompanhamento e na fiscalização dos atos praticados pelo Poder Executivo, em especial pelos setores responsáveis pela administração dos assuntos de defesa nacional.

Para as políticas e estratégias de defesa nacional, destaca-se a observância das regras constitucionais e do modelo democrático adotados pelo Brasil, notadamente para o uso da força ou da violência, que se encontra sempre sujeito às normas de direito, mediante responsabilização dos atores políticos e públicos que atuam no setor.

No campo das relações internacionais, os documentos estruturantes de defesa abrigam o primado da cooperação e da solução pacífica de controvérsias, sem abrir mão da soberania e afastando modelos de supraestatalidade e de compartilhamento de poder estatal. Há uma concentração de esforços para manter a estabilidade, a paz e o desenvolvimento da América do Sul, sempre na perspectiva republicana de democracia como fundamento das relações no bloco regional, o que proporciona mecanismos de convergência e solidariedade no enfrentamento de problemas comunitários, considerando-se que a noção de integração não significa perdimento da identidade dos povos, mas sim a multiplicidade de expectativas para compor amplos consensos.

A quadrienalidade da revisão dos textos da PDN e da END não afasta o continuado processo de acompanhamento, fiscalização e transparência de que são responsáveis o Executivo e o Legislativo, informando à sociedade os resultados alcançados e os desafios para a função defesa nacional, na linha de, pelo esclarecimento e resguardado o sigilo legal, possam promover um programa de educação em defesa, ampliando as bases de legitimidade para as escolhas políticas e para os recursos públicos aplicados, por exemplo, em pessoal, estruturas orgânicas e equipamentos.

O sistema de pesos e contrapesos vigente na partilha de competências entre Presidente da República, Congresso Nacional e Poder Executivo evita que a politização da função defesa nacional chegue ao nível de disputa ideológica por posições injustificáveis e concorrentes. Mas o debate em torno das escolhas políticas deve ser mantido e ampliado na perspectiva suprapartidária sem, contudo, excluir os argumentos advindos das mais diversas correntes de pensamento, de modo a que prevaleça, pelo debate, o que corresponda aos princípios republicanos consagrados na Constituição.

A expectativa é de que o Congresso Nacional reflita e consiga apresentar aperfeiçoamentos aos textos da PND e da END, cujos documentos, 
juntamente com o LBDN, correspondem ao processo histórico de amadurecimento democrático do Brasil, de modo que as edições anteriores permanecem compreendidas no conjunto de ações do Estado voltadas para a função de defesa.

\section{REFERÊNCIAS}

Aguiar, Roberto A. R. de. 2000. Os Filhos da Flecha do Tempo - Pertinência e Rupturas. Brasília: Letraviva.

Bobbio, Norberto. 2003. O Problema da Guerra e as Vias da Paz. São Paulo: Editora UNESP.

Bobbio, Norberto. 2006. O Futuro da Democracia. São Paulo: Paz e Terra.

Borges, José Souto Maior. 2005. Curso de Direito Comunitário. São Paulo: Saraiva.

Brasil. 1948. Decreto $n^{\circ}$ 25. 660, de 13 de outubro de 1948. Manda executar o Tratado Interamericano de Assistência Recíproca, firmado no Rio de Janeiro, a 2 de setembro de 1947, por ocasião da Conferência Interamericana para a Manutenção da Paz e da Segurança no Continente. Disponível em: <http://legis. senado. leg. $\mathrm{br} /$ legislacao/ListaTextoSigen. action?norma $=4483298 \mathrm{\& id}=14228972 \& i d B i n a r i$ $\mathrm{o}=15637432 \& \mathrm{mime}=$ application $/ \mathrm{rtf}>$. Acesso em: 6 fev. 2018 .

Brasil. 1980. Decreto $n^{0}$ 85. O50, de 18 de agosto de 1980. Promulga o Tratado de Cooperação Amazônica, concluído entre os governos da República da Bolívia, da República Federativa do Brasil, da República da Colômbia, da República do Equador, da República Cooperativa da Guiana, da República do Peru, da República do Suriname e da República da Venezuela. Disponível em: <http://legis. senado. gov. br/legislacao/ListaTextoSigen. action? norma $=507690 \& i d=14245550 \& i d B i$ nario $=15706610 \&$ mime $=$ application $/ \mathrm{rtf}>$. Acesso em: 7 fev. 2018.

Brasil. 1988. Constituição da República Federativa do Brasil de 1988. Disponível em: <http://www. planalto. gov. br/ccivil_03/constituicao/constituicao. htm>. Acesso em: 15 dez. 2017.

Brasil. 1991. Decreto $n^{\circ}$ 350, de 21 de novembro de 1991. Promulga o Tratado para a Constituição de um Mercado Comum entre a República Argentina, a República Federativa do Brasil, a República do Paraguai e a República Oriental do Uruguai (TRATADO MERCOSUL). Disponível em: < http://www. planalto. gov. br/ccivil_03/decreto/1990-1994/do350. htm>. Acesso em: 6 fev. 2018.

Brasil. 1996. Decreto $n^{\circ}$ 1. 901, de 9 de maio de 1996. Promulga o Protocolo Adicional ao Tratado de Assunção sobre a Estrutura Institucional do MERCOSUL 
(Protocolo de Ouro Preto), de 17 de dezembro de 1994. Disponível em: <http:// www. planalto. gov. br/ccivil_03/decreto/d1901. htm>. Acesso em: 6 fev. 2018.

Brasil. 1996. Documento sobre Política de Defesa Nacional. Revista Parcerias Estratégicas, 1, 2, 7-15 e 16-18, dez.

Brasil. 1999. Lei Complementar $n^{\circ} 97$, de 9 de junho de 1999. Dispõe sobre as normas gerais para a organização, o preparo e o emprego das Forças Armadas. Disponível em: < http://www. planalto. gov. br/ccivil_03/leis/lcp/Lcp97. htm>. Acesso em: 15 dez. 2017.

Brasil. 2002. Decreto $n^{\circ}$ 4. 210, de 24 de abril de 2002. Promulga o Protocolo de Ushuaia sobre Compromisso Democrático no Mercosul, Bolívia e Chile. Disponível em: <http://www. planalto. gov. br/ccivil_03/decreto/2002/d4210. htm>. Acesso em: 6 fev. 2018.

Brasil. 2002. Decreto $n^{\circ}$ 4. 387, de 25 de setembro de 2002. Promulga o Protocolo de Emenda ao Tratado de Cooperação Amazônica. Disponível em: <https://www. planalto. gov. br/ccivil_03/decreto/2002/d4387. htm>. Acesso em: 7 fev. 2018.

Brasil. 2005. Decreto $n^{\circ}$ 5. 484, de 30 de junho de 2005. Aprova a Política de Defesa Nacional, e dá outras providências. Disponível em: <http://www. planalto. gov. br/ccivil_03/_ato2004-2006/2005/decreto/d5484. htm>. Acesso em: 15 dez. 2017.

Brasil. 2006. Decreto Legislativo $n^{\circ} 44$, de 12 de abril de 2006. Aprova o texto do Acordo de Sede entre o Governo da República Federativa do Brasil e a Organização do Tratado de Cooperação Amazônica - OTCA, celebrado em Brasília, em 13 de dezembro de 2002. Disponível em: <http://legis. senado. gov. br/legislacao/ ListaTextoSigen. action? norma $=578870 \& i d=14359586 \&$ \&idBinario $=15837850 \&$ mime=application $/ \mathrm{rtf}>$. Acesso em: 7 fev. 2018.

Brasil. 2006. Decreto $n^{0}$ 5. 819, de 26 de junho de 2006. Promulga o Acordo de Sede entre o Governo da República Federativa do Brasil e a Organização do Tratado de Cooperação Amazônica, celebrado em Brasília, em 13 de dezembro de 2002. Disponível em: <https://www. planalto. gov. br/ccivil_03/_Ato20042006/2006/Decreto/D5819. htm>. Acesso em: 7 fev. 2018.

Brasil. 2007. Decreto $n^{\circ}$ 6. 084, de 19 de abril de 2007. Promulga o Acordo Quadro de Cooperação em Matéria de Defesa entre a República Federativa do Brasil e a Argentina, celebrado em Puerto Iguazú, em 30 de novembro de 2005. Disponível em: <http://www. planalto. gov. br/ccivil_03/_Ato2007-2010/2007/Decreto/ D6084. htm>. Acesso em: 6 fev. 2018. 
Brasil. 2007. Decreto $n^{0}$ 6. 105, de 30 de abril de 2007. Promulga o Protocolo Constitutivo do Parlamento do Mercosul, aprovado pela Decisão no 23/05, do Conselho do Mercado Comum, assinado pelos Governos da República Federativa do Brasil, da República Argentina, da República do Paraguai e da República Oriental do Uruguai, em Montevidéu. Disponível em: <http://www. planalto. gov. br/ccivil_03/_Ato2007-2010/2007/Decreto/D6105. htm>. Acesso em: 6 fev. 2018.

Brasil. 2008. Decreto $n^{0}$ 6. 703, de 18 de dezembro de 2008. Aprova a Estratégia Nacional de Defesa, e dá outras providências. Disponível em: $<$ http://www. planalto. gov. br/ccivil_03/_ato2007-2010/2008/decreto/d6703. htm>. Acesso em: 15 dez. 2017.

Brasil. 2010. Lei Complementar $n^{\circ} 136$, de 25 de agosto de 2010. Altera a Lei Complementar n. 97, de 9 de junho de 1999, que "dispõe sobre as normas gerais para a organização, o preparo e o emprego das Forças Armadas", para criar o Estado-Maior Conjunto das Forças Armadas e disciplinar as atribuições do Ministro de Estado da Defesa. Disponível em: <http://www. planalto. gov. br/ ccivil_03/leis/lcp/Lcp136. htm>. Acesso em: 15 dez. 2017.

Brasil. Ministério da Defesa. 2012. Livro Branco de Defesa Nacional. Disponível em: <www. defesa. gov. br/projetosweb/livrobranco/>. Acesso em: 4 dez. 2012.

Brasil. Congresso Nacional. 2012. Comissão Mista de Controle das Atividades de Inteligência. Parecer n. 51, de 2012-CN. Sobre os textos da proposta de Política de Defesa Nacional (sic), da Estratégia Nacional de Defesa e o Livro Branco de Defesa Nacional. Diário Oficial da União, Seção 1, p. 1-2, de 26 de setembro de 2013.

Brasil. Congresso Nacional. 2013. Decreto Legislativo n. 373, de 2013. Aprova a Política Nacional de Defesa, a Estratégia Nacional de Defesa e o Livro Branco de Defesa Nacional, encaminhados ao Congresso Nacional pela Mensagem n. 83, de 2012 (Mensagem n. 323, de 17 de julho de 2012, na origem). Diário Oficial da União, Seção 1, p. 1-2, de 26 de setembro de 2013.

Brasil. 2013. Decreto $n^{o}$ 8. 128, de 22 de outubro de 2013. Promulga o Acordo Quadro sobre Cooperação em Matéria de Defesa entre o Governo da República Federativa do Brasil e o Governo da República do Peru, firmado em Brasília, em 9 de novembro de 2006. Disponível em: <https://www. planalto. gov. br/ccivil_03/_ato2011-2014/2013/decreto/d8128. htm>. Acesso em: 7 fev. 2018.

Brasil. Presidência da República. Gabinete de Segurança Institucional. Ministério da Defesa. 2017. Proposta de texto para a Política Nacional de Defesa. Disponível em: $<$ http://legis. senado. leg. br/sdleg-getter/documento?dm=5063108\&dispositio $\mathrm{n}=$ inline $>$. Acesso em: 15 dez. 2017. 
Brasil. Presidência da República. Gabinete de Segurança Institucional. Ministério da Defesa. 2017. Proposta de texto para a Estratégia Nacional de Defesa. Disponível em: <http://legis. senado. leg. br/sdleg-getter/documento?dm=5063 108\&dispo sition=inline $>$. Acesso em: 15 dez. 2017.

Brasil. Congresso Nacional. Comissão Mista de Controle das Atividades de Inteligência. 2017. Parecer (CN) n. 1, de 19 de outubro de 2017. Sobre os textos da proposta de Política de Defesa Nacional (sic), da Estratégia Nacional de Defesa e o Livro Branco de Defesa Nacional. Disponível em: <http://legis. senado. leg. br/ sdleg-getter/documento? $\mathrm{dm}=7237929 \&$ disposition=inline $>$. Acesso em: $15 \mathrm{dez}$. 2017.

Carvalho, José Murilo de. 2005. Forças Armadas e Política no Brasil. Rio de Janeiro: Jorge Zahar Ed.

Carvalho, José Murilo de. 2006. A Construção da Ordem: a Elite Política Imperial. Teatro de Sombras: a Política Imperial. Rio de Janeiro: Civilização Brasileira.

Clastres, Pierre. 2010. Arqueologia da Violência. São Paulo: Cosac Naify.

Coni, Luis Claudio. 2006. A Internacionalização do Poder Constituinte. Porto Alegre: Sergio Antonio Fabris Editor.

D’Araujo, Maria Celina; Castro, Celso. 2000. Democracia e Forças Armadas no Cone Sul. Rio de Janeiro: Editora FGV.

Dahl, Robert. 2009. Sobre a Democracia. Brasília: Editora Universidade de Brasília.

Diáz Revorio, Francisco Javier. 1997. La Constitución como Orden Abierto. Madrid: MacGraw-Hill.

Ferrajoli, Luigi. 2002. A Soberania no Mundo Moderno: Nascimento e Crise do Estado Nacional. São Paulo: Martins Fontes.

Ferreira, Oliveiros S. 2003. Ideias para a Concepção Estratégica: a Defesa Nacional e o Projeto Nacional. Seminário de Política de Defesa para o Século XXI, 2002, Brasília. Brasília: Senado Federal - Secretaria Especial de Editoração e Publicações.

Furtado, Celso. 1991. Formação Econômica do Brasil. São Paulo: Companhia Editora Nacional.

Holanda, Sergio Buarque de. 1936. Raízes do Brasil. Rio de Janeiro: José Olympo. Kant, Immanuel. 2004. A Paz Perpétua e Outros Opúsculos. Lisboa: Edições 70. 
Lefort, Claude. 1991. Pensando o Político: Ensaios sobre Democracia, Revolução e Liberdade. Rio de Janeiro: Paz e Terra.

Lewandowski, Enrique Ricardo. 2004. Globalização, Regionalização e Soberania. São Paulo: Juarez de Oliveira.

Loewenstein, Karl. 1986. Teoría de la Constitución. Barcelona: Ariel.

Losano, Mario. 2007. Os grandes sistemas jurídicos. São Paulo: Martins Fontes.

Maliska, Marcos Augusto. 2006. Estado e Século XXI: a Integração Supranacional sob a Ótica do Direito Constitucional. Rio de Janeiro: Renovar.

Müller, Friedrich. 2004. Fragmento (sobre) o Poder Constituinte do Povo. São Paulo: Revista dos Tribunais.

Oliveira, Eliézer Rizzo de. 2007. Democracia e Defesa Nacional: uma Agenda a Partir do Poder Legislativo. In Oliveira, Eliézer Rizzo de (Org. ). Segurança e Defesa Nacional: de Competição à Cooperação Regional. São Paulo: Fundação Memorial da América Latina.

Rawls, John. 2002. Uma Teoria da Justiça. São Paulo: Companhia das Letras.

Ribeiro, Darcy. 2006. O Povo Brasileiro: a Formação e o Sentido do Brasil. Companhia das Letras.

Rocha, Maria Elizabeth Guimarães Teixeira; Domingues, Leyza Ferreira; Ribeiro, Elisa de Sousa. 2008. A Adesão da Venezuela ao Mercosul: o Manifesto da Integração Expansionista. Revista de Informação do Legislativa, Brasília, 45, 177, 7-18, jan. / mar.

Santos, Boaventura de Souza. 1989. Introdução a uma Ciência Pós-Moderna. Rio de Janeiro: Graal.

Schmitt, Carl. 1968. Legalidad y Legitimidade. Madrid: Aguillar.

Schmitt, Carl. 2001. El concepto de lo "político". In Schmitt, Carl, Teólogo de la Política. México: Fondo de Cultura Económica.

Silva, Paulo Napoleão Nogueira. 2000. Direito Constitucional do Mercosul. Rio de Janeiro: Forense.

União das Nações Sul-Americanas. Conselho de Defesa Sul-Americano. 2013. Plano de Ação do Conselho de Defesa Sul-Americano 2013. Disponível em: <http:// 
ceed. unasursg. org/Portugues/o9-Downloads/Port-PA/PA-CDS-2013-PORT. pdf $>$. Acesso em: 15 dez. 2017.

Vergopoulos, Kostas. 2005. Globalização, o Fim de um Ciclo: Ensaio sobre a Instabilidade Internacional. Rio de Janeiro: Contraponto.

Weber, Max. 1996. A Ética Protestante e o Espírito do Capitalismo. São Paulo: Pioneira.

Villoro, Luis. 1985. O Conceito de Ideologia, e Outros Ensaios. Fundo de Cultura Econômica: México.

Virilio, Paul; Lotringer, Sylvere. 1984. Guerra Pura: a Militarização do Cotidiano. São Paulo: Brasiliense. 


\section{NOTAS}

1. A política de defesa nacional foi provada pelo Decreto $\mathrm{n}^{\circ} 5.484$, de 30 de junho de 2005, e entrou em vigor no dia $1^{\circ}$ de julho de 2005 . Anteriormente, em 1996, a Revista Parcerias Estratégicas publicou o Documento sobre Política de Defesa Nacional.

2. Decreto $\mathrm{n}^{\mathrm{o}}$ 5.484, de 30 de junho de 2005. Posteriormente, passou-se a intitular Política de Defesa Nacional (PDN).

3. Decreto $\mathrm{n}^{\circ} 6.703$, de 18 de dezembro de 2008.

4. Texto disponível em: <www.defesa.gov.br/projetosweb/livrobran$\mathrm{co} />$. Acessado em: 4 dez. 2012.

5. Art. 84, inciso VI, “a”, da Constituição de 1988 (ato cuja natureza está limitada a dispor sobre organização e funcionamento da administração federal, desde que não implique aumento de despesa, criação ou extinção de órgãos públicos).

6. Decreto $\mathrm{n}^{\mathrm{o}}$ 5.484, de 30 de junho de 2005.

7. Decreto $n^{\circ} 6.703$, de 18 de dezembro de 2008

8. Decreto Legislativo $n^{\circ}$ 373, de 2013.

9. Parecer (CN) n. 1, de 19 de outubro de 2017 (matéria em tramitação).

10. Art. $4^{\circ}$, incisos I a X, da Constituição de 1988.

11. Art. $4^{\circ}$, parágrafo único, da Constituição de 1988.

12. Decreto $\mathrm{n}^{\mathrm{O}} 4.210$, de 24 de abril de 2002.

13. Decreto $\mathrm{n}^{\mathrm{o}} 350$, de 21 de novembro de 1991; Decreto ${ }^{\circ} 1.901$, de 9 de maio de 1996; Decreto $n^{\circ} 4.210$, de 24 de abril de 2002; e Decreto $n^{\circ}$ 6.105 , de 30 de abril de 2007.

14. Decreto $\mathrm{n}^{\mathrm{o}} 25.660$, de 13 de outubro de 1948.

15. Subscrito originalmente por República Dominicana, Guatemala, Costa Rica, Peru, El Salvador, Panamá, Paraguai, México, Haiti, Uruguai, Estado Unidos da América, Argentina, Venezuela, Chile, Honduras, Cuba, Bolívia, Colômbia e Brasil. Consta que Bolívia, Cuba, Equador, México Nicarágua e Venezuela não mais figuram como membros do Tratado.

16. Decreto $\mathrm{n}^{\mathrm{o}}$ 2.864, de 7 de dezembro de 1998.

17. Decreto ${ }^{\circ}$ 85.050, de 18 de agosto de 1980; Decreto ${ }^{\circ} 4.387$, de 25 de setembro de 2002; Decreto Legislativo $\mathrm{n}^{\circ} 44$, de 12 de abril de 2006; e Decreto $\mathrm{n}^{\mathrm{o}} 5.819$, de 26 de junho de 2006.

18. Decreto $\mathrm{n}^{\mathrm{o}} 8.128$, de 22 de outubro de 2013.

19. Decreto $n^{\circ} 6.084$, de 19 de abril de 2007.

20. PND submetida ao Congresso Nacional. 2. Contexto (..). 2.1. Fundamentos, item 2.1.5.

21. PND submetida ao Congresso Nacional. 2. Contexto (..). 2.3. O ambiente internacional, item 2.3.7. 
22. PND submetida ao Congresso Nacional. 2. Contexto (..). 2.3. O ambiente internacional, itens 2.3.10 e 2.3.11.

23. PND submetida ao Congresso Nacional. 3. Concepção (..). 3.2, VIII.

24. PND submetida ao Congresso Nacional. 4. Objetivos (..). 4.2, V e VI.

25. END submetida ao Congresso Nacional. 4. Estratégias (..). OND-5: Contribuir (..). ED-11 Promoção (..).

26. END submetida ao Congresso Nacional. 4. Estratégias (..). OND-5: Contribuir (..). ED-11 Promoção (..). AED 44.

27. END submetida ao Congresso Nacional. 4. Estratégias (..). OND-5: Contribuir (..). ED-11 Promoção (..). AED 45.

28. END submetida ao Congresso Nacional. 4. Estratégias (..). OND-5: Contribuir (..). ED-1 1 Promoção (..). AED 46.

29. A título de ilustração, a respeito da Organização do Tratado do Atlântico Norte, sugere-se a leitura de A estratégia da decepção, de Paul Virilio (São Paulo: Estação Liberdade, 2000).

30. END submetida ao Congresso Nacional. 4. Estratégias (..). OND-5: Contribuir (..). ED-12 Promoção (..). AED 47.

31. END submetida ao Congresso Nacional. 4. Estratégias (..). OND-5: Contribuir (..). ED-12 Promoção (..). AED 48.

32. END submetida ao Congresso Nacional. 4. Estratégias (..). OND-5: Contribuir (..). ED-12 Promoção (..). AED 49.

33. END submetida ao Congresso Nacional. 4. Estratégias (..). OND-5: Contribuir (..). ED-12 Promoção (..). AED 50.

34. END submetida ao Congresso Nacional. 4. Estratégias (..). OND-5: Contribuir (..). ED-12 Promoção (..). AED 51.

35. PND submetida ao Congresso Nacional. 2. Contexto (..). 2.1. Fundamentos, item 2.1.3.

36. PND submetida ao Congresso Nacional. 4. Objetivos (..). 4.1 e 4.2, I.

37. END submetida ao Congresso Nacional. 3. Fundamentos. 3.1. Poder Nacional.

38. PND submetida ao Congresso Nacional. 2. Contexto (..). 2.1. Fundamentos, item 2.1.3.

39. END submetida ao Congresso Nacional. 3. Fundamentos. 3.1. Poder Nacional.

40. PND submetida ao Congresso Nacional. 4. Objetivos (..). 4.2, I.

41. Para ampliar estudos sobre o sistema de pesos e contrapesos entre Executivo de Legislativo, cabe o aprofundamento da análise das competências exclusivas do Congresso Nacional (art. 49, incisos I, II, IV, V, IX, X, XIV) e privativas do Presidente da República (art. 84, incisos I, VI, VIII, IX, X, XIII, XVII, XVIII, XIX, XX, XXII, XXIII e XXIV), previstas na Constituição de 1988. 
42. Art. 142, parte final, da Constituição de 1988.

43. Decreto ${ }^{\circ}$ 3.897, de 24 de agosto de 2001.

44. END submetida ao Congresso Nacional. 3. Fundamentos. 3.3. Setor de Defesa.

45. Art. 89 da Constituição.

46. Art. 91 da Constituição. 
POLÍTICA E ESTRATÉGIA NACIONAIS DE DEFESA:

INTEGRAÇÃO E CONSENSOS POLÍTICOS

\section{RESUMO}

O presente artigo apresenta reflexões a respeito das propostas de textos da Política Nacional de Defesa e da Estratégia Nacional de Defesa que se encontram sob a apreciação do Congresso Nacional brasileiro. A contribuição acadêmica se dirige aos enunciados de integração sul-americana, de cooperação e participação internacional do Brasil, bem como às peculiaridades da democracia e do constitucionalismo brasileiros como elementos de limitação e de legitimação do poder político, dos meios diplomáticos e do setor de defesa nacional. A metodologia de abordagem foi construída com base na legislação e nas propostas apresentadas pelo Poder Executivo, mencionando-se possíveis contribuições teóricas.

Palavras-chave: Defesa Nacional; Política; Estratégia; Constitucionalismo.

\section{ABSTRACT}

This article presents reflections on the proposals of texts of the National Defense Policy and the National Defense Strategy that are under the Brazilian National Congress' appreciation. The academic contribution is directed to the statements of South American integration, cooperation and international participation of Brazil, as well as the peculiarities of Brazilian democracy and constitutionalism as elements of limitation and legitimation of political power, diplomatic means and the defense sector national. The approach methodology was built based on the legislation and the proposals presented by the Federal Government, mentioning possible theoretical contributions.

Keywords: National Defense; Policy; Strategy; Constitutionalism. 